\title{
Enhancing AI based evaluation for smart cultivation and crop testing using agro-datasets
}

\author{
Shibin David ${ }^{1, *}$, R.S. Anand ${ }^{2}$, Martin Sagayam ${ }^{3}$ \\ ${ }^{1}$ Department of Computer Science and Engineering, Karunya Institute of Technology and Sciences, Coimbatore, India \\ Email: zionshibin@gmail.com \\ ${ }^{2}$ Department of mechanical engineering, Karunya Institute of Technology and Sciences, Coimbatore, India \\ Email: bethelanand.r.s@gmail.com \\ ${ }^{3}$ Department of Electronics and Communication Engineering, Coimbatore, India \\ Email: martinsagayam.k@gmail.com \\ *Corresponding Author: Shibin David, Email: zionshibin@gmail.com
}

How to cite this paper: Shibin David, R.S. Anand, Martin Sagayam (2020). Enhancing AI based evaluation for smart cultivation and crop testing using agro-datasets. Journal of Artificial Intelligence and Systems, 2, 149-167.

https://doi.org/10.33969/AIS.2020.21010.

Received: March 26, 2020

Accepted: April 20, 2020

Published: April 21, 2020

Copyright $(\subset 2020$ by author(s) and Institute of Electronics and Computer. This work is licensed under the Creative Commons Attribution International License (CC BY 4.0).

http://creativecommons.org/licenses/by/4.0/

(c) (i) Open Access

\begin{abstract}
In India, Agriculture is considered as the backbone of the country where 70 percent of the economy relies upon it. It requires the involvement of many natural resources including land, water, and energy. An astonishing factor is that 60 percent of the water diverted or pumped for irrigation is wasted via runoff into waterways or evapotranspiration. Although chemical fertilizers improve the growth of plants and increase the yields of fruits and vegetables in a relatively short period of time, there are certain shortcomings of using chemical fertilizers as an opponent to the use of organic fertilizers obtained from natural wealth. The persistent use of chemical fertilizers causes the pollution of ground water sources, or leaching. Since the chemicals present in the chemical fertilizers spoil the soil scraps, the inference of this will be a high impact on the soil with reduced drainage and in the air circulation. The synthesizers that are used for farming will adversely affect the nature and the $\mathrm{pH}$ of the soil. Nowadays water scarcity is considered to be major concern in the cultivation process. Alongside, yet another major problem faced in cultivation is the usage of lots of fertilizers which makes the land infertile.. In this paper, the nature of the work to sense various factors such as atmospheric temperature, soil moisture, rain, and $\mathrm{pH}$ value through a GSM module. Using the aforementioned factors, the farmers and landlords can able to predict how much water is required for the land and how much nutrients required for land. The technological advancement in artificial intelligence paves a way to detect the sensed values and predict whether a crop could be planted on the soil present in a region.
\end{abstract}

\section{Keywords}

Arduino UNO, Soil moisture sensor, pH sensor, Temperature sensor, Rain drop sensor, GSM module, Agriculture land 


\section{Introduction}

Agriculture is one of the most important areas of human activity. Agriculture needs the perseverance of various natural resources, including land, water, and energy [1]. Agriculture is the biggest water user, with irrigation accounting for $70 \%$ of global water withdrawals. As the report from the UN food and water organization says, an astounding $60 \%$ of the water side-tracked or impelled for irrigation is wasted through runoff into waterways or evapotranspiration [2,3]. Although chemical fertilizers improve the growth of plants and increase the yields of fruits and vegetables in a relatively short period of time, there are certain disadvantages of using chemical fertilizers as critical organic fertilizers derived from natural sources $[1,2]$.

- The persistent use of chemical fertilizers causes the pollution of ground water sources, or leaching. As the chemicals within the chemical fertilizers destroy soil crumbs; the results are extremely compacted soil with reduced evacuation and air circulation.

- The artificial chemicals within the chemical fertilizers adversely have an effect on the health of naturally found soil micro-organisms by poignant the soil $\mathrm{pH}$ scale [1].

- The scope of this paper is to reduce water scarcity, to reduce the use of inorganic fertilizers, to sense various factors of the soil such as temperature, moisture, rain, $\mathrm{pH}$ content and to predict the amount of water and nutrients to be required for the soil [4].

- Water scarcity and infertile lands are the primary concern in this work where smart cultivation will prove to assist the farmers despite of the use of existing preventive measures.

\section{Related works}

\subsection{Existing system}

Traditional way of farming is otherwise termed to be the primogenital food production system and the origin of agriculture where it is being practiced for too many years. It also acts as the key source for refining the farming in terms of conventional, modern and organic farming which promotes genetic diversity also. Increasing environmental awareness farmers [2-3,5] following modern and scientific understanding of ecology, soil science, irrigation, using traditional method like crop rotations, compost / dung fertilizer, natural weed, biological pest control to protect the ecosystem. One major problem of traditional farming is farmers have to be present in the field all the time [5-7]. Another major problem is over pumping of 
Shibin David et al.

water to the field results in wastage of water [3]. The existing system contains only two or three sensors in the sensing part like soil moisture sensor and temperature sensor, humidity sensor and temperature sensor, rain drop sensor, humidity sensor and soil moisture sensor and so on.

\subsection{Motivation}

The motivation behind this work is by sensing various factors such as atmospheric temperature, soil moisture, rain, $\mathrm{pH}$ value. Using these factors we can able to predict how much water is required for the land and how much nutrients required for land. So this can be narrowed down to a specific crop.

\section{Experimental setup}

The system is developed by two different ways for smart cultivation system a) System Module b) Implementation.

\subsection{System Module}

The system module is explained in this section. Fig.1. shows the flow of the architecture for smart cultivation system. Here we are having various sensors such as temperature, soil moisture, raindrop, $\mathrm{pH}$ and GSM. This hardware can be deployed in any type of crop to sense the value of the soil.

A Sequence diagram is an interaction diagram that shows how processes operate with one another and in what order. It is a construct of a Message Sequence Chart. A sequence diagram shows object interactions arranged in time sequence. It depicts the objects and classes involved in the scenario and the sequence of messages exchanged between the objects needed to carry out the functionality of the scenario. Sequence diagrams are typically associated with use case realizations in the Logical View of the system under development. Sequence diagrams are sometimes called event diagrams or event scenarios.

LM35 temperature sensor as shown in Fig 2 is used to measure hotness or coldness of an object. The output of LM35 temperature sensor is in ${ }^{\circ} \mathrm{C}$. The temperature sensor operates in the range from $-55^{\circ} \mathrm{C}$ to $150^{\circ} \mathrm{C}$ [8].

The factors such as temperature value, $\mathrm{pH}$ value and moisture value measures the strength of the crop to be cultivated in a region. The nominal range of these factors is tabulated in Table.1. Based on the constant metrics, the soil moisture, rain intensity and $\mathrm{pH}$ value is tested using the arduino program and the same is communicated to the agriculturists. 


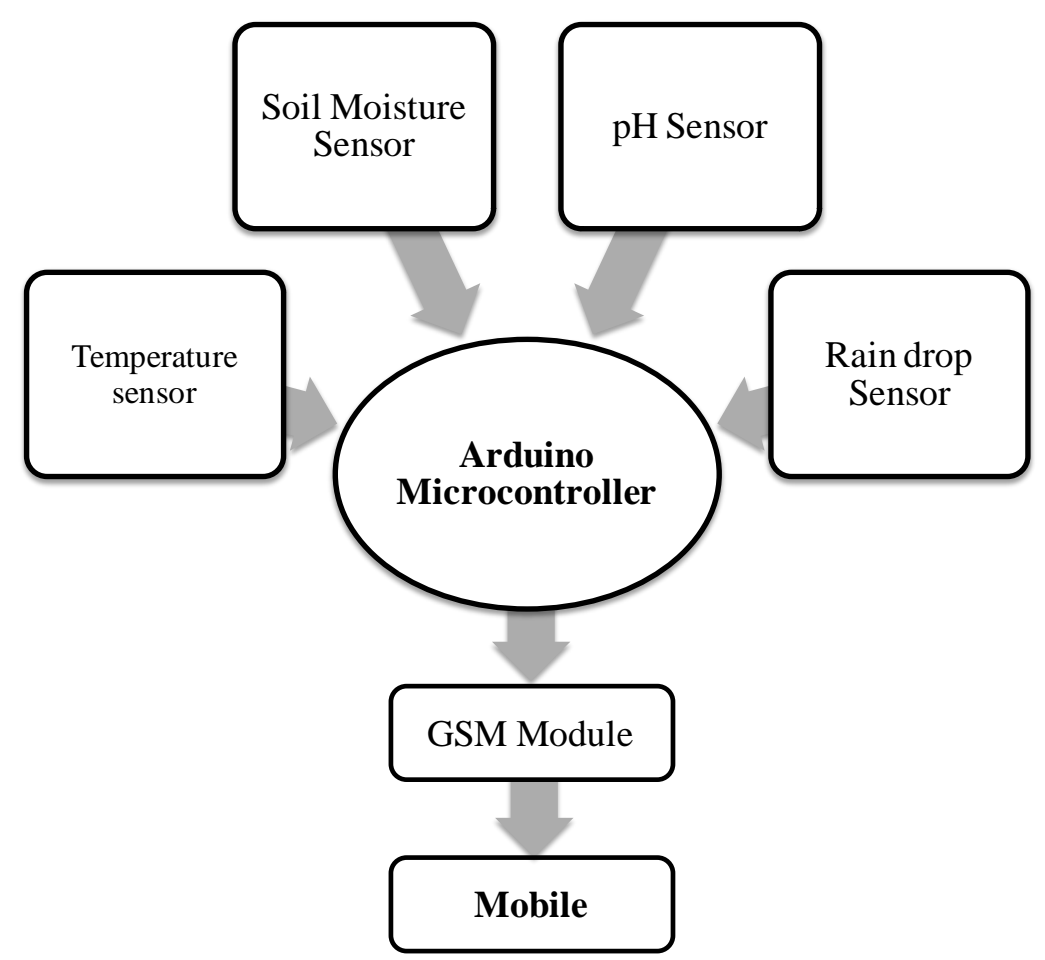

Figure 1. Flow diagram for smart cultivation

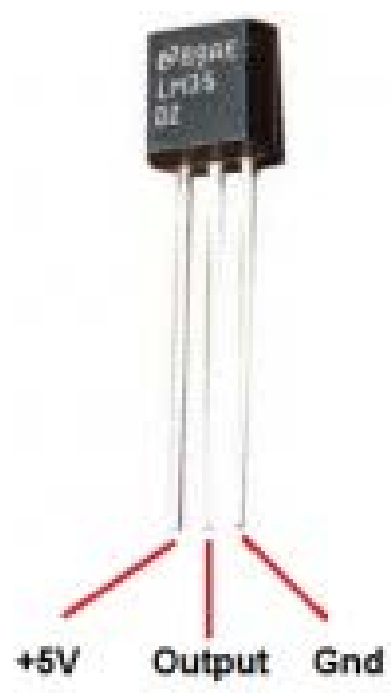

Figure 2. LM35 temperature sensor

Soil moisture sensor is used to estimate the soil volumetric content of the soil. It monitors the soil content to control the irrigation system. The soil moisture sensor 
Shibin David et al.

is depicted in Fig 3. Rain drop sensor as shown in Fig 4 is a rain sensing module which is used to measure the rain fall intensity [9,11]. It is used to calculate the amount of rain over a particular period.

$\mathrm{pH}$ sensor is used to sense the $\mathrm{pH}$ value of the soil. If the $\mathrm{pH}$ value is less than 7 , then it is acidic. If it is equal to 7 , then it is neutral. If it is greater than 7 , then it is basic or alkaline. It is displayed in Fig 5.

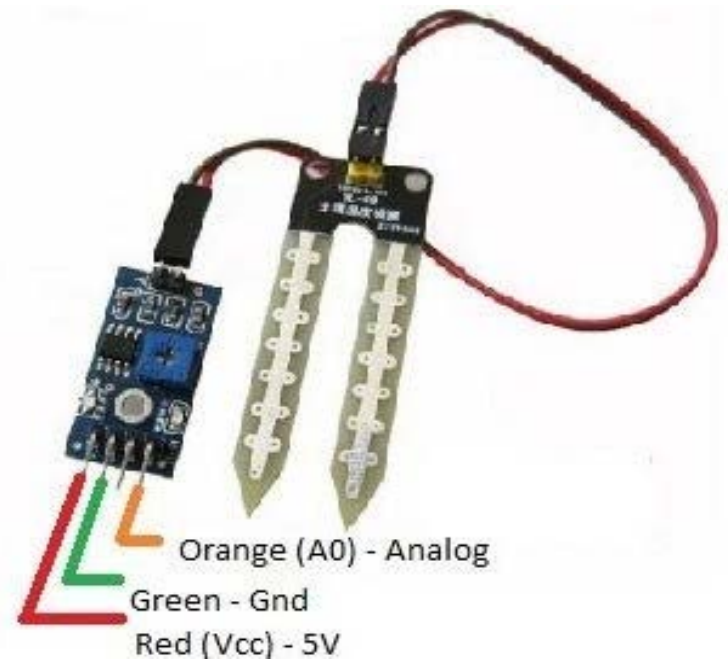

Figure 3. Soil Moisture sensor

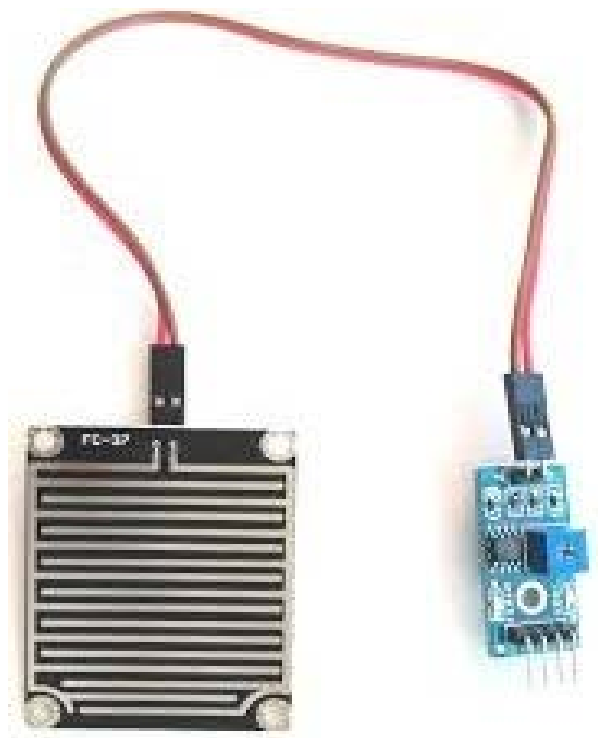

Figure 4. Rain drop sensor 


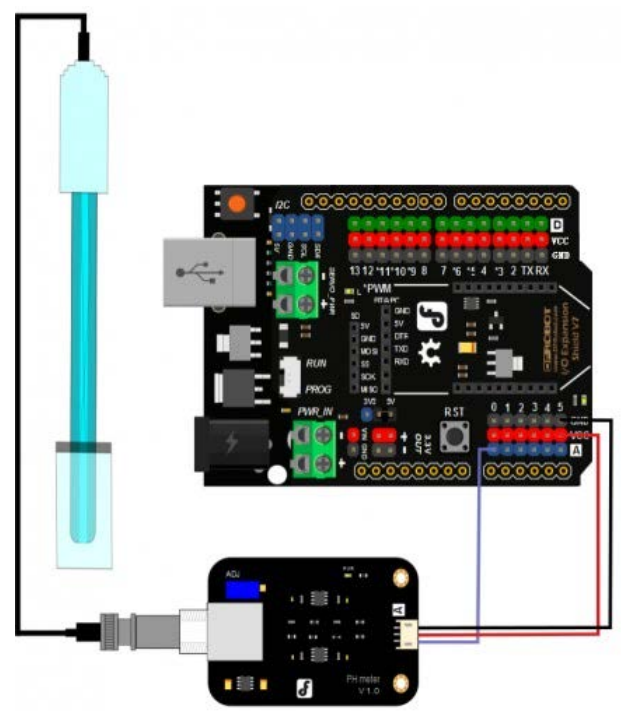

Figure 5. $\mathrm{pH}$ sensor

\subsection{Implementation}

The values of temperature sensor, soil moisture sensor, $\mathrm{pH}$ sensor and rain drop sensor are given as input to Arduino [4]. The Output of Arduino is given as input to GSM module. The output of GSM module is sent as notification to mobile user as SMS.

The values from the sensors are sensed and stored in Arduino and corresponding action is done [11]. For temperature sensor the temperature value ranges from $16^{\circ} \mathrm{C}$ to $27^{\circ} \mathrm{C}[10,13-14]$. If the value is less than or greater than the required temperature it intimates the user via SMS else it display data to the user via SMS.

For soil moisture sensor the moisture value for dry, medium, wet soil is $14 \%$, $18 \%$ and $20 \%$ respectively. If the value is less than or greater than the required moisture content it intimates the user via SMS else it display data to the user via SMS. For $\mathrm{pH}$ sensor the $\mathrm{pH}$ value ranges from 6.5 to 8 . If the value is less than or greater than the required $\mathrm{pH}$ value it intimates the user via SMS else it display data to the user via SMS.

The values of the sensor are sensed and given to Arduino [18]. The Arduino detects the data and intimate the user via GSM.GSM is global system for mobile communication that is used for transmitting data and voice services $[4,10]$. The mobile user gets the information as SMS via GSM. Sensing of various factors can be narrowed down to a specific crop. 
Shibin David et al.

\subsection{Steps to implement the module}

There are certain functional requirements which may sense and provide the statistical analysis report for implementing the smart cultivation system into the agricultural lands.

Procedure for arduino setup:

- Install arduino 1.6.10

- Open the sketch book

- Connect the sensors, arduino and GSM (Fig.6)

- Type the code in the sketch book

- Verify the execution of the code (Fig.7, Fig.8, Fig.9, Fig.10, Fig.11 depicts it)

- Upload the code

- If the channel connectivity between the user's mobile and sensors are fine, then the output message will reach the user

A minimal arduino $\mathrm{C} / \mathrm{C}++$ sketch which is used for implementation, as seen by the Arduino IDE programmer, consists of two functions including setup and loop functions [12] [17].

- Setup: This function is called once when a sketch starts after power-up or reset. It is used to initialize variables, input and output pin modes, and other libraries needed in the sketch.

- Loop: After setup has been called, function loop is executed repeatedly in the main program. It controls the board until the board is powered off or is reset. Most Arduino boards contain a light-emitting diode (LED) and a load resistor connected between pin 13 and ground, which is a convenient feature for many tests and program functions.

The same connectivity is made along with the soil moisture sensor, raindrop sensor, temperature sensor, $\mathrm{pH}$ sensors [16]. 
Shibin David et al.

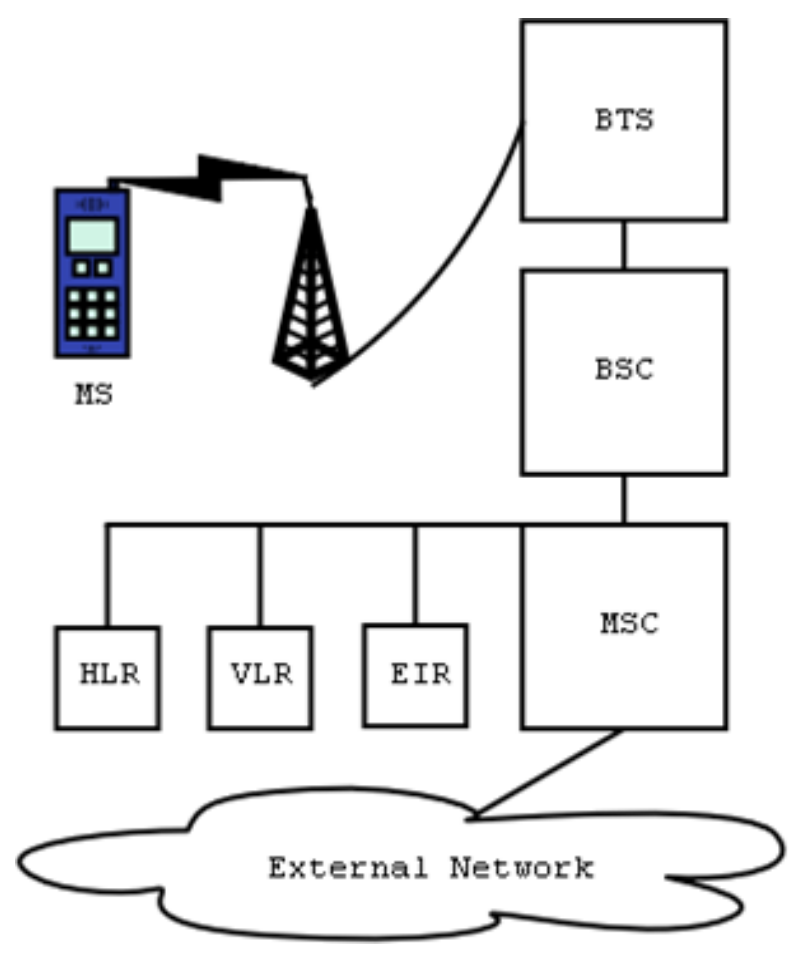

Figure 6. GSM Module

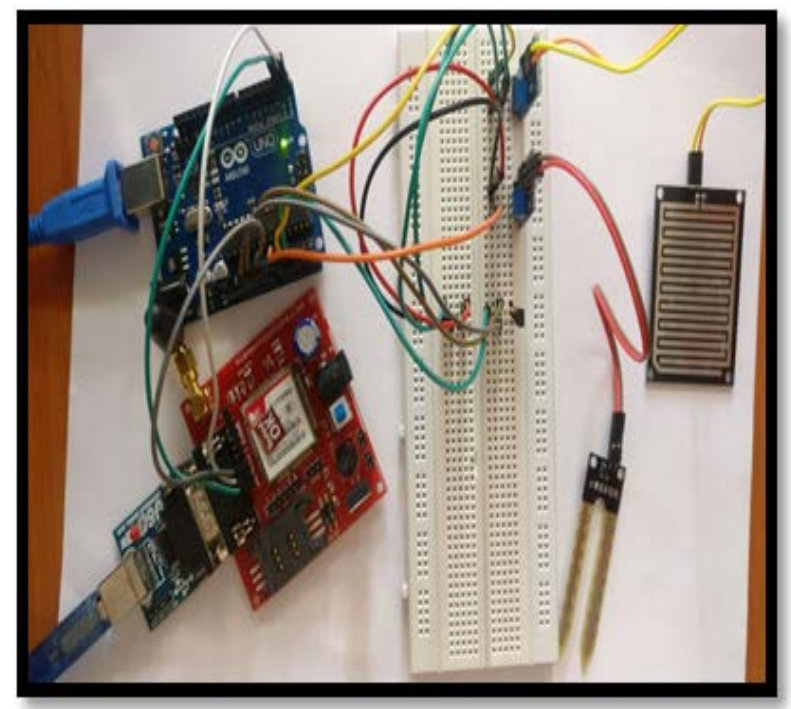

Figure 7. Connectivity between the sensors, arduino and GSM 
Shibin David et al.

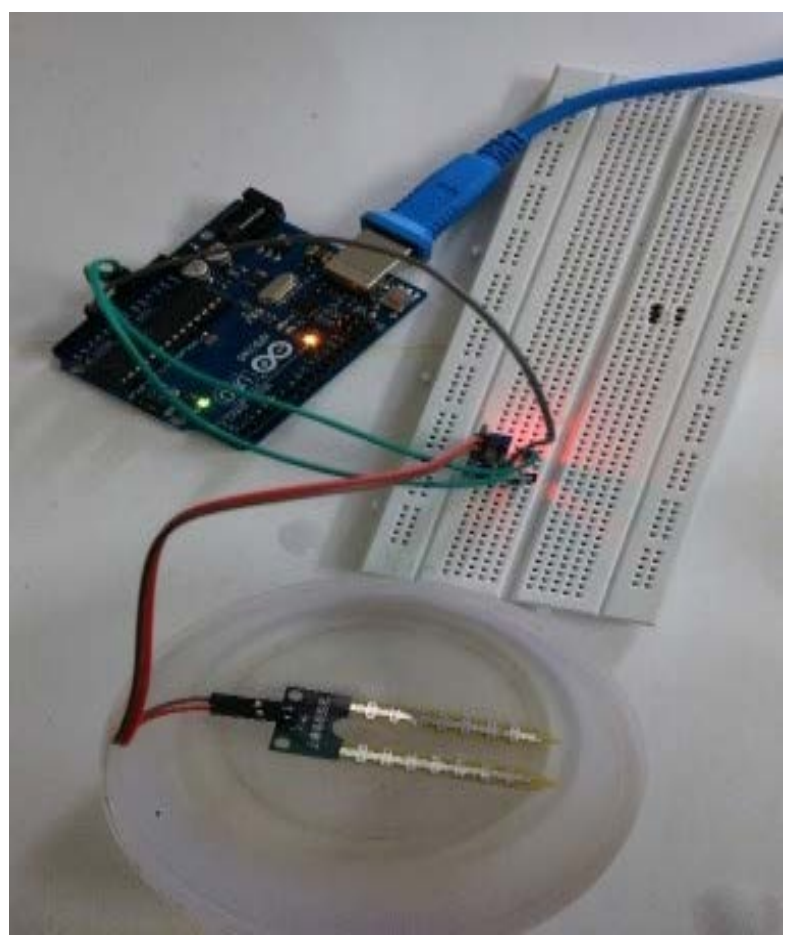

Figure 8. Testing using soil moisture sensor

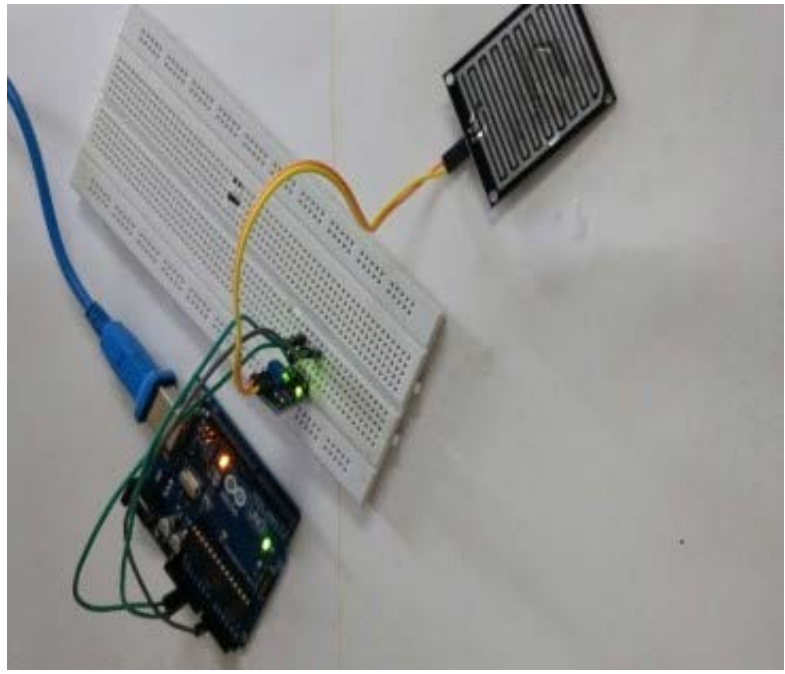

Figure 9. Raindrop sensor 
Shibin David et al.

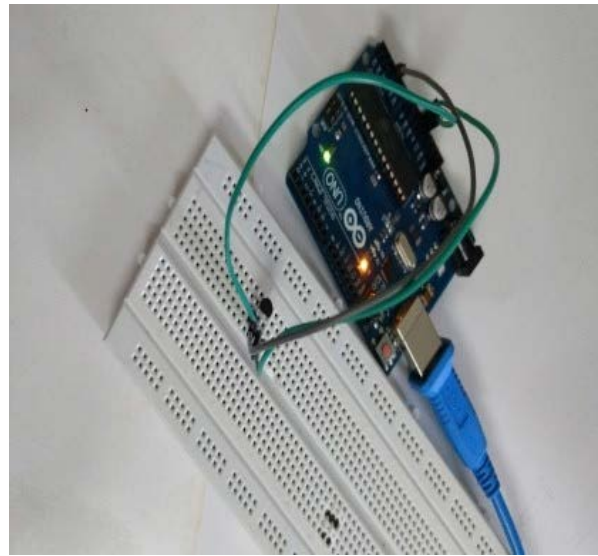

Figure 10. Temperature sensor

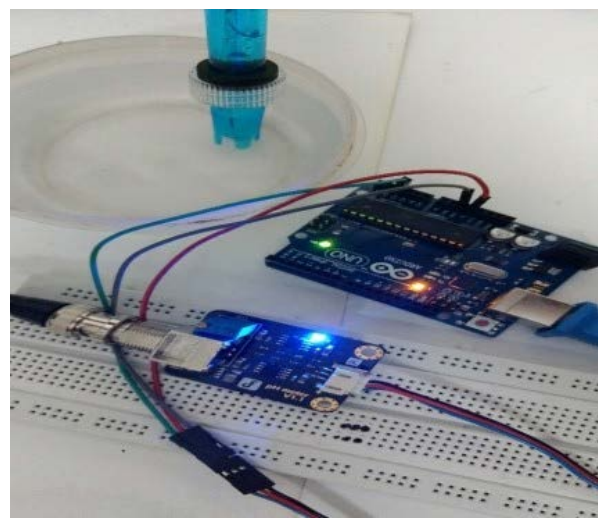

Figure 11. $\mathrm{pH}$ sensor

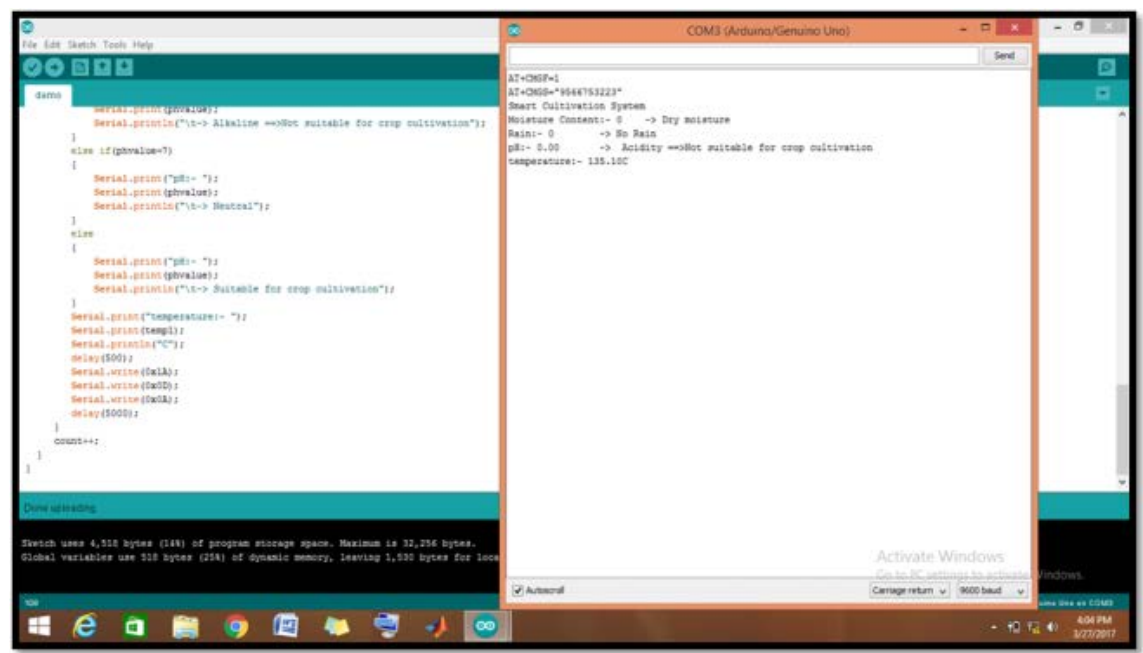

Figure 12. Outcome of the smart cultivation 
Shibin David et al.

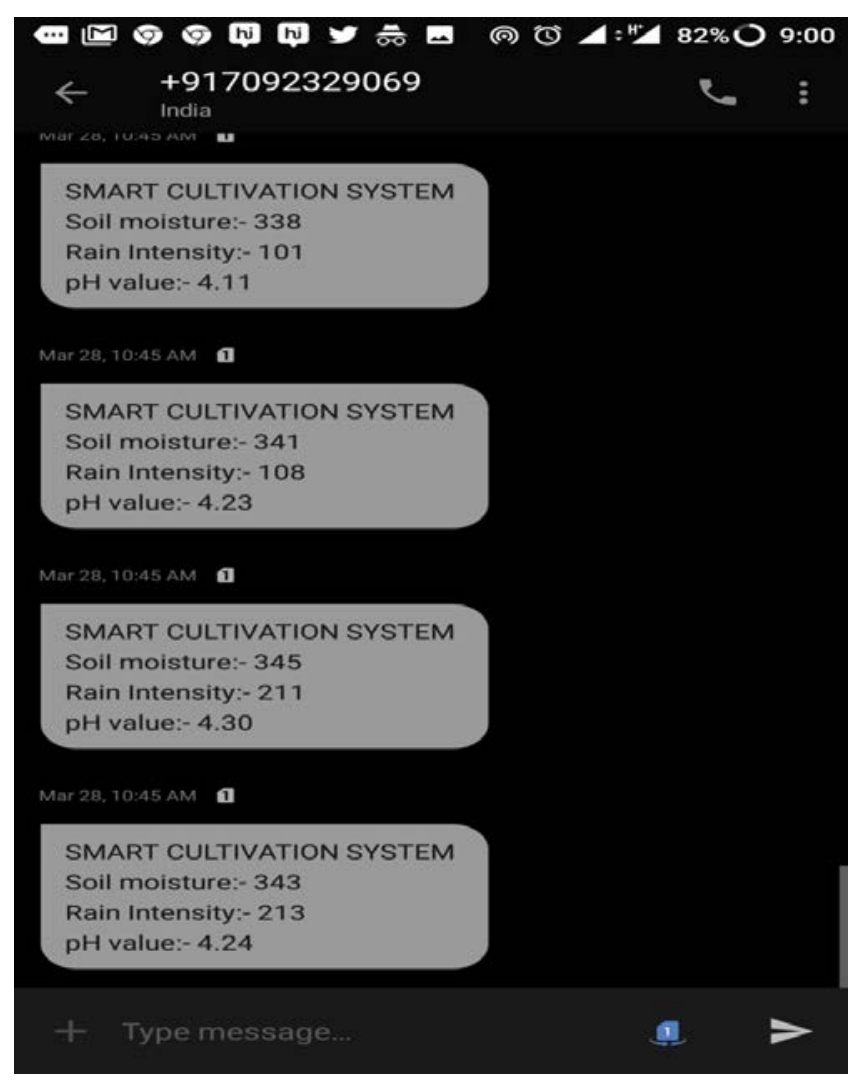

Figure 13. Sensed output from smart cultivation

The outcome including the moisture, $\mathrm{pH}$, temperature and acidity will be sent to the user as depicted in the Fig 12

\section{Results and Discussions}

\subsection{Experimental analysis}

There are certain functional requirements which may sense and provide the statistical analysis based on the range of factors prevailing for the crops presented in Table. 1.

This statistics will help the agriculturists to sense the $\mathrm{pH}$ value, determine the metrics to know the strength of the soil, create evidence against the strength using Bayes algorithm and provide the results.

The functional requirements include

- $\quad$ Sensing the $\mathrm{pH}$ value

- $\quad$ Sensing the atmospheric temperature

- $\quad$ Sending SMS via GSM 
- $\quad$ Sensing the moisture content

Table 1. Range of factors prevailing the crops.

\begin{tabular}{cccc}
\hline Crop & Temperature value & $\mathbf{p H}$ value & Moisture value \\
\hline Paddy & $16-27^{\circ} \mathrm{C}$ & $6.5-8.5$ & $\begin{array}{c}\text { Dry- } 14 \% \\
\text { Medium- } 18 \% \\
\text { High- } 20 \%\end{array}$ \\
Peppers & $\begin{array}{c}14-16^{\circ} \mathrm{C} \text { (night) } \\
22-30^{\circ} \mathrm{C} \text { (day) }\end{array}$ & $5.5-6.5$ & $60-65 \%$ \\
Egg plant & $\begin{array}{c}15-18^{\circ} \mathrm{C} \text { (night) } \\
22-26^{\circ} \mathrm{C} \text { (day) }\end{array}$ & $5.5-7.0$ & $60-70 \%$ \\
Cucumber & $22-28^{\circ} \mathrm{C}$ (day) & $5.5-6.5$ & $70-90 \%$ \\
Potato & $18-20^{\circ} \mathrm{C}$ (night) & & \\
\hline
\end{tabular}

The values of temperature sensor, soil moisture sensor, $\mathrm{pH}$ sensor and rain drop sensor are given as input to Arduino [19]. The Output of Arduino is given as input to GSM module. The output of GSM module is sent as notification to mobile user as SMS. The values from the sensors are sensed and stored in Arduino and corresponding action is done. For temperature sensor the temperature value ranges from $16^{\circ} \mathrm{C}$ to $27^{\circ} \mathrm{C}$. If the value is less than or greater than the required temperature it intimates the user via SMS else it display data to the user via SMS.

For soil moisture sensor the moisture value for dry, medium, wet soil is $14 \%$, $18 \%$ and $20 \%$ respectively. If the value is less than or greater than the required moisture content it intimates the user via SMS else it display data to the user via SMS.

For $\mathrm{pH}$ sensor the $\mathrm{pH}$ value ranges from 6.5 to 8 , If the value is less than or greater than the required $\mathrm{pH}$ value it intimates the user via SMS else it display data to the user via SMS. The values of the sensor are sensed and given to Arduino. The Arduino detects the data and intimate the user via GSM. GSM is global system for mobile communication that is used for transmitting data and voice services. The mobile user gets the information as SMS via GSM. Sensing of various factors can be narrowed down to a specific crop. Our project deals with paddy. 
Table 2. Test case using soil sensors.

\begin{tabular}{|c|c|c|c|c|}
\hline $\begin{array}{l}\text { Test case } \\
\text { Name }\end{array}$ & $\begin{array}{c}\text { Test case } \\
\text { procedure }\end{array}$ & Expected Result & Obtained result & $\begin{array}{c}\text { Status } \\
\text { Pass/fail }\end{array}$ \\
\hline \multirow{3}{*}{$\begin{array}{c}\text { Sense } \\
\text { soil } \\
\text { moisture }\end{array}$} & $\begin{array}{l}\text { Detect the } \\
\text { heavy } \\
\text { moisture of } \\
\text { the soil }\end{array}$ & Moisture $>80$ & Moisture = 81 & Pass \\
\hline & $\begin{array}{l}\text { Detect the } \\
\text { medium } \\
\text { moisture of } \\
\text { the soil }\end{array}$ & Moisture $>25 \|<80$ & Moisture $=58.90$ & Pass \\
\hline & $\begin{array}{l}\text { Detect the } \\
\text { dry moisture } \\
\text { of the soil }\end{array}$ & Moisture $<25$ & Moisture $=23$ & Pass \\
\hline
\end{tabular}

Table 3. Test case using rain sensor.

\begin{tabular}{|c|c|c|c|c|}
\hline $\begin{array}{l}\text { Test case } \\
\text { Name }\end{array}$ & $\begin{array}{c}\text { Test case } \\
\text { procedure }\end{array}$ & $\begin{array}{l}\text { Expected } \\
\text { Result }\end{array}$ & Obtained result & $\begin{array}{c}\text { Status } \\
\text { Pass/fail }\end{array}$ \\
\hline \multirow{3}{*}{$\begin{array}{l}\text { Sense rain } \\
\text { intensity }\end{array}$} & $\begin{array}{l}\text { Detect } \\
\text { heavy rain }\end{array}$ & $\begin{array}{l}\text { Rain } \\
\text { intensity }>300\end{array}$ & Rain intensity $=1020$ & Pass \\
\hline & $\begin{array}{l}\text { Detect } \\
\text { moderate } \\
\text { rain }\end{array}$ & $\begin{array}{l}\text { Rain intensity } \\
>300 \|<500\end{array}$ & Rain intensity $=363$ & Pass \\
\hline & $\begin{array}{l}\text { Detect no } \\
\text { rain }\end{array}$ & $\begin{array}{l}\text { Rain } \\
\text { intensity }>500\end{array}$ & Rain intensity= 237 & Pass \\
\hline
\end{tabular}

Table 2 deals with the test case of deploying soil moisture sensor, Table 3 indicates the use of rain sensors, Table 4 denotes that temperature sensor could be used to test the temperature and Table 5 indicates the deployment of $\mathrm{pH}$ sensors.

Table 2 depicts the status of sensing the soil moisture upon heavy ratio, moderate ratio and dry ratio and infers whether cultivation can be made on the soil or not. The moisture level obtained when heavy ratio of moisture is found to be 81 whereas the moderate ratio and dry ratio is found to be 58.90 and 23 respectively. Hence, it is 
concluded that the smart cultivation can be performed on all the levels of moisture available in the soil.

Table 4. Atmospheric temperature testing.

\begin{tabular}{lllll}
\hline $\begin{array}{l}\text { Test } \\
\text { Name }\end{array}$ & $\begin{array}{l}\text { Test case } \\
\text { procedure }\end{array}$ & $\begin{array}{l}\text { Expected } \\
\text { Result }\end{array}$ & $\begin{array}{l}\text { Obtained } \\
\text { result }\end{array}$ & $\begin{array}{l}\text { Status } \\
\text { Pass/fail }\end{array}$ \\
\hline $\begin{array}{l}\text { Sense } \\
\text { atmospheric } \\
\text { temperature }\end{array}$ & $\begin{array}{l}\text { Detect } \\
\text { temperature }\end{array}$ & $\begin{array}{l}\text { Temperature } \\
>15 \|<20\end{array}$ & $\begin{array}{l}\text { Temperature }= \\
19.35\end{array}$ & Pass \\
\hline
\end{tabular}

Table 3 shows the sensing of rain intensity upon various climatic conditions. The soil sensor is used to sense the rain intensity and it outlays 1020, 363, 237 for heavy intensity, moderate intensity and low intensity respectively.

The atmospheric temperature range on an optimum should lie between $15^{\circ} \mathrm{C}$ and $20^{\circ} \mathrm{C}$. As tabulated in Table 4, while the atmospheric temperature was sensed using the sensor, it was detected and found that it lies in the range of $19.35^{\circ} \mathrm{C}$.

The soil nature can be classified into three categories which includes acidic, neutral and alkaline. When the test case is fixed for acidic nature of the soil, the sensor senses the soil and produces the $\mathrm{pH}$ result as 4.09 which are favorable over the expected value. The test is done using the soil sensor which is kept and tested at a $\mathrm{pH}$ range less than 5.0. This indicates that the soil can used for smart cultivation in terms of acidic nature of the soil. When the test case is fixed for neutral nature of the soil, the sensor senses the soil and produces the $\mathrm{pH}$ result as 7 which are favorable over the expected value. The test is done using the soil sensor which is kept and tested at a pH range equal to 7.0. This indicates that the soil can used for smart cultivation in terms of neutral nature of the soil. When the test case is fixed for alkaline nature of the soil, the sensor senses the soil and produces the $\mathrm{pH}$ result as 7.5 which are favorable over the expected value. The test is done using the soil sensor which is kept and tested at a $\mathrm{pH}$ range greater than 7.0. This indicates that the soil can used for smart cultivation in terms of alkaline nature of the soil. 
Table 5. $\mathrm{pH}$ value testing.

\begin{tabular}{|c|c|c|c|c|}
\hline $\begin{array}{l}\text { Test case } \\
\text { Name }\end{array}$ & $\begin{array}{l}\text { Test case } \\
\text { procedure }\end{array}$ & $\begin{array}{l}\text { Expected } \\
\text { Result }\end{array}$ & Obtained result & $\begin{array}{c}\text { Status } \\
\text { Pass/fail }\end{array}$ \\
\hline \multirow{3}{*}{$\begin{array}{l}\text { Sense pH } \\
\text { value }\end{array}$} & $\begin{array}{l}\text { Detect acidic } \\
\text { nature of the soil }\end{array}$ & $\mathrm{pH}<5$ & $\mathrm{pH}=4.09$ & Pass \\
\hline & $\begin{array}{l}\text { Detect neutral } \\
\text { nature of the soil }\end{array}$ & $\mathrm{pH}=7$ & $\mathrm{pH}=7$ & Pass \\
\hline & $\begin{array}{l}\text { Detect alkaline } \\
\text { nature of the soil }\end{array}$ & $\mathrm{pH}>7$ & $\mathrm{pH}=7.5$ & Pass \\
\hline
\end{tabular}

\subsection{Theoretical analysis and discussions}

Let ' $\mathrm{A}$ ' be the chance of deploying the paddy crop in the fields, ' $\mathrm{B}$ ' be the chance of growth in the crop deployed in the field.

Assume $\neg \mathrm{A} \rightarrow \neg \mathrm{B}$

This implies, $\mathrm{B} \rightarrow \mathrm{A}$ sensor,

The chance of growth in the field is possible.

Table 6. Paddy data set.

\begin{tabular}{|c|c|c|c|}
\hline \multirow{6}{*}{ 会 } & $\begin{array}{c}\text { Temperature } \\
\left({ }^{\circ} \mathrm{C}\right)\end{array}$ & $\mathbf{p H}$ & $\begin{array}{c}\text { Moisture } \\
\text { (\%) }\end{array}$ \\
\hline & 3 & 2.3 & 29 \\
\hline & 11 & 4.2 & 25 \\
\hline & 19 & 7.3 & 20 \\
\hline & 29 & 9.2 & 13 \\
\hline & 36 & 10.6 & 7 \\
\hline
\end{tabular}

The dataset represented in Table.6 depicts the various factors to determine the strength of soil, to cultivate paddy crop in the local area based on the dataset randomized variable [20-24] containing the set of values which includes its temperature, $\mathrm{pH}$ value and moisture level. Here the set $S=\{19,7.3,20\}$ consisting the test variables to be incorporated into Naive Bayes algorithm [20, 24-26] in order to test the accuracy an possibility of the growth of paddy crop in our local area.

Let the chance of positive growth be calculated as $P(B \mid A)=A \rightarrow B$, and the prior probability of planting the crop in the field can be denoted as $\alpha(\mathrm{A})$.

The probability of growth in the suitable environment is denoted as $\mathrm{P}(\mathrm{A} \mid \mathrm{B})=1$ which impliesB $\rightarrow \mathrm{A}$.

Based on the Naïve Bayes theorem, 


$$
P(A \mid B)=\frac{P(A) \cdot P(B / A)}{P(B)}
$$

Similarly,

$$
\begin{aligned}
& \mathrm{P}(\mathrm{A} \mid \mathrm{B})=\frac{\mathrm{P}(\mathrm{B} / \mathrm{A}) \cdot \alpha(\mathrm{A})}{\mathrm{P}(\mathrm{B} \mid \mathrm{A}) \cdot \alpha(\mathrm{A})+\mathrm{P}(\mathrm{B} \mid \neg \mathrm{A}) \mathrm{P}(\mathrm{B}) \cdot \alpha(\neg \mathrm{A})} \\
& \mathrm{P}(\mathrm{A})=\sum_{i=1}^{i=n} \text { Decisions on }\left\{\mathrm{P}_{1}, \mathrm{P}_{2}, \mathrm{P}_{3} \ldots . \mathrm{P}_{\mathrm{n}}\right\} \\
& \mathrm{P}(\mathrm{B})=\sum_{j=1}^{j=n} \text { Growth of }\left\{\mathrm{P}_{1}, \mathrm{P}_{2}, \mathrm{P}_{3} \ldots \ldots \mathrm{P}_{\mathrm{n}}\right\} \\
& \mathrm{P}(\mathrm{B} \mid \mathrm{A})=\frac{\text { Decisions upon evidences }}{\text { Growth }} \\
& \mathrm{P}(\mathrm{B} \mid \mathrm{A})=\sum_{i=1}^{i=n} \frac{\mathrm{D}\left\{\mathrm{P}_{1}, \mathrm{P}_{2}, \mathrm{P}_{3} \ldots . \mathrm{P}_{\mathrm{n}}\right\}}{\mathrm{G}\left\{\mathrm{P}_{1}, \mathrm{P}_{2}, \mathrm{P}_{3} \ldots . . \mathrm{P}_{\mathrm{n}}\right\}} \\
& \mathrm{P}(\mathrm{A} \mid \mathrm{B})=\frac{\mathrm{P}(\mathrm{A}) \cdot \mathrm{P}(\mathrm{B} \mid \mathrm{A})}{\mathrm{P}(\mathrm{B})} \\
& \mathrm{P}(\mathrm{A} \mid \mathrm{B})=\frac{\mathrm{P}(\mathrm{B} \mid \mathrm{A}) \cdot \alpha(\mathrm{A})}{\mathrm{P}(\mathrm{B} \mid \mathrm{A}) \cdot \alpha(\mathrm{A})+\mathrm{P}(\mathrm{B} \mid \neg \mathrm{A}) \cdot \alpha(\neg \mathrm{A})}
\end{aligned}
$$

Propositional logic,

$$
\begin{gathered}
(\neg \mathrm{A} \rightarrow \neg \mathrm{B}) \rightarrow(\mathrm{B} \rightarrow \mathrm{A}) \\
\mathrm{P}(\mathrm{B} \mid \mathrm{A})=(\mathrm{A} \rightarrow \mathrm{B}) \\
\mathrm{P}(\mathrm{A} \mid \mathrm{B})=1=\mathrm{B} \rightarrow \mathrm{A} \\
\mathrm{P}(\mathrm{A} \mid \mathrm{B})=\frac{\mathrm{P}(\mathrm{B} / \mathrm{A}) \text {. Prior probability }}{\mathrm{P}(\mathrm{B} / \mathrm{A}) \text {. Prior probability } \mathrm{P}(\mathrm{B} / \text { Propositional logic). } \alpha \text { (Propositional logic })}
\end{gathered}
$$

Let the propositional logic applied over A be $\alpha(\neg \mathrm{A})$

$$
\mathrm{P}(\mathrm{A} \mid \mathrm{B})=\frac{\mathrm{P}(|\mathrm{B}| \mathrm{A}) \cdot \alpha(\mathrm{A})}{\mathrm{P}(\mathrm{B} \mid \mathrm{A}) \cdot \alpha(\mathrm{A})+\mathrm{P}(\mathrm{B} \mid \neg \mathrm{A}) \alpha(\neg \mathrm{A})}
$$

Evaluating the variables present in Table.6 based on Bayes theorem,

$$
\begin{gathered}
P(A)=0.526, P(B)=0.2618, P(B / A)=0.326 \\
P(A / B)=0.655=65.5 \%
\end{gathered}
$$

The decision indicates that there is a possibility of $65.5 \%$ growth of paddy crop in our locality is possible and it is determined that the factor supporting such growth is available in our locality. 
Shibin David et al.

\section{Conclusions}

Factors such as temperature, soil moisture, $\mathrm{pH}$ value and rain are therefore sensed to predict how much water is required and the fertility of soil for a particular crop. Thus this way makes the farmers to do cultivation in a smarter way. As of this work, the KR representation and Bayes algorithm has been deployed to check whether a particular crop can be grown on the soil present in a region. This work can be further improved by using wireless module technology with addition of NPK (Nitrogen, Phosphorus and Potassium) sensor which decides how much extra nutrient contents are to be added in the soil to increase crop fertility and also by using automatic water supply combining with IOT concept.

\section{Acknowledgements}

The study on the cultivation of paddy and its practices has been made from the web portal TNAU.

\section{Conflicts of Interest}

There is no conflict of interest.

\section{References}

[1] Parameswaran, G. and Sivaprasath, K. (2016) Arduino based smart drip irrigation system using Internet of Things. International Journal of Engineering Science and Computing, 5518.

[2] Angel, C., \& Asha, S. (2015). A study on developing a smart environment in agricultural irrigation technique. International Journal of Ambient Systems and Applications (IJASA), 3, 11-17.

[3] Jagannathan, S., \& Priyatharshini, R. (2015). Smart farming system using sensors for agricultural task automation. In 2015 IEEE Technological Innovation in ICT for Agriculture and Rural Development (TIAR) IEEE. 49-53.

[4] Devika, S. V., Khamuruddeen, S., Khamurunnisa, S., Thota, J., \& Shaik, K. (2014). Arduino based automatic plant watering system. International Journal of Advanced Research in Computer Science and Software Engineering, 4(10), 449-456.

[5] Laursen, M. S., Midtiby, H. S., Krüger, N., \& Jørgensen, R. N. (2014). Statistics-based segmentation using a continuous-scale naive Bayes approach. Computers and electronics in agriculture, 109, 271-277.

[6] Hadi, W. E., Al-Radaideh, Q. A., \& Alhawari, S. (2018). Integrating associative rule-based classification with Naïve Bayes for text classification. Applied Soft Computing, 69, 344-356.

[7] Seka, D., Bonny, B. S., Yoboué, A. N., Sié, S. R., \& Adopo-Gourène, B. A. (2019). Identification of maize (Zea mays L.) progeny genotypes based on two probabilistic approaches: Logistic regression and naïve Bayes. Artificial 
Intelligence in Agriculture, 1, 9-13.

[8] Mukhopadhyay, S., Chakraborty, S., Bhadoria, P. B. S., Li, B., \& Weindorf, D. C. (2020). Assessment of heavy metal and soil organic carbon by portable $\mathrm{X}$-ray fluorescence spectrometry and NixPro ${ }^{\mathrm{TM}}$ sensor in landfill soils of India. Geoderma Regional, 20, e00249.

[9] Deng, F., Zuo, P., Wen, K., \& Wu, X. (2020). Novel soil environment monitoring system based on RFID sensor and LoRa. Computers and Electronics in Agriculture, 169, 105169.

[10] Kassaye, K. T., Boulange, J., Saito, H., \& Watanabe, H. (2020). Monitoring soil water content for decision supporting in agricultural water management based on critical threshold values adopted for Andosol in the temperate monsoon climate. Agricultural Water Management, 229, 105930.

[11] Zhou, W., Xu, Z., Ross, D., Dignan, J., Fan, Y., Huang, Y., \& Li, B. (2019). Towards water-saving irrigation methodology: Field test of soil moisture profiling using flat thin mm-sized soil moisture sensors (MSMSs). Sensors and Actuators B: Chemical, 298, 126857

[12] Domínguez-Niño, J. M., Oliver-Manera, J., Girona, J., \& Casadesús, J. (2020). Differential irrigation scheduling by an automated algorithm of water balance tuned by capacitance-type soil moisture sensors. Agricultural Water Management, 228, 105880.

[13] Castrignanò, A., Buttafuoco, G., Quarto, R., Parisi, D., Rossel, R. V., Terribile, F., \& Venezia, A. (2018). A geostatistical sensor data fusion approach for delineating homogeneous management zones in Precision Agriculture. Catena, 167, 293-304.

[14] Leue, M., Hoffmann, C., Hierold, W., \& Sommer, M. (2019). In-situ multi-sensor characterization of soil cores along an erosion-deposition gradient. Catena, 182, 104140.

[15] Radovanović, M., Vasiljević, D., Krstić, D., Antić, I., Korzhyk, O., Stojanović, G., \& Škrbić, B. D. (2019). Flexible sensors platform for determination of cadmium concentration in soil samples. Computers and Electronics in Agriculture, 166, 105001.

[16] Roy, S. K., \& De, D. (2020). Genetic Algorithm based Internet of Precision Agricultural Things (IopaT) for Agriculture 4.0. Internet of Things, 100201.

[17] Corani, G., \& Zaffalon, M. (2008). JNCC2: An extension of naive Bayes classifier suited for small and incomplete data sets. Environmental Modelling and Software, 23(7), 960-961.

[18] Barca, E., Castrignanò, A., Ruggieri, S., \& Rinaldi, M. (2020). A new supervised classifier exploiting spectral-spatial information in the Bayesian framework. International Journal of Applied Earth Observation and Geoinformation, 86, 101990.

[19] Bargiel, D. (2017). A new method for crop classification combining time series of radar images and crop phenology information. Remote sensing of environment, 198, 369-383.

[20] Diengdoh, V. L., Ondei, S., Hunt, M., \& Brook, B. W. (2020). A validated ensemble method for multinomial land-cover classification. Ecological Informatics, 56, 101065. 
Shibin David et al.

[21] Ip, R. H., Ang, L. M., Seng, K. P., Broster, J. C., \& Pratley, J. E. (2018). Big data and machine learning for crop protection. Computers and Electronics in Agriculture, 151, 376-383.

[22] Ramya, M. C., Lokesh, V., Manjunath, T. N., \& Hegadid, R. S. (2015). A predictive model construction for mulberry crop productivity. Procedia Computer Science, 45, 156-165.

[23] Keswani, B., Mohapatra, A.G., Mohanty, A. et al. Adapting weather conditions based IoT enabled smart irrigation technique in precision agriculture mechanisms. Neural Comput \& Applic 31, 277-292 (2019).

[24] Jatin Arora, Utkarsh Agrawal, and Prerna Sharma (2020). Classification of Maize leaf diseases from healthy leaves using Deep Forest. Journal of Artificial Intelligence and Systems, 2, 14-26.

[25] Deepak Gupta, Prerna Sharma, Krishna Choudhary, Kshitij Gupta, Rahul Chawla,Ashish Khanna, Victor Hugo C. de Albuquerque (2020), "Artificial plant optimization algorithm to detect infected leaves using machine learning", Epert Systems.

[26] Aditya Khamparia, Gurinder Saini, Deepak Gupta, Ashish Khanna, Shrasti Tiwari, Victor Hugo C. de Albuquerque (2019), "Seasonal crop disease prediction and classification using Deep Convolutional Encoder network", Circuits, Systems, and Signal Processing. 